\title{
Lo que quedó de Cuba cuando los rusos se fueron a la órbita. Algunas características del espacio ficcional post- soviético en la más reciente ciencia-ficción cubana
}

\author{
What Remained of Cuba, After the Russians went into Orbit. Some \\ characteristics of the Post-Soviet Fctional Space in Newest Cuban
}

\begin{abstract}
Yoss (JosÉ Miguel SÁNCHEZ GóMEZ
Unión de Escritores y Artistas de Cuba · yoss00@cubarte.cult.cu

Considerado el autor de ciencia ficción más relevante de Cuba en la actualidad, se graduó de Biología en la Universidad de la Habana en 1991. Narrador, crítico y ensayista, es miembro de la UNEAC desde 1994 y ha publicado más de 30 libros entre Cuba y en el extranjero, con los que ha obtenido diversos premios dentro y fuera del país.
\end{abstract}

RECIBIDO: 6 DE FEBRERO DE 2015

ACEPTADO: 3 DE JUNIO DE 2015

Resumen: Este texto analiza las características de la ciencia ficción cubana post-soviética, después del colapso de la Unión Soviética y el Periodo Especial de los años noventa. Se centra particularmente en la producción más reciente de Vladimir Hernández Pacín, Eric Flores Taylor y Jesús B. Minsal, entre otros autores. Analizando sus novelas y cuentos, el autor establece una triple categorización de la ciencia ficción cubana postsoviética, según la mayor o menor presencia de Rusia como elemento referencial. Estas tres aproximaciones serían: primera, la total ausencia de Rusia; segunda, identificada como 'nostalgia post-soviética' y tercera, catalogada como ucronía, en donde Rusia sigue jugando un rol activo y agente, a pesar de las circunstancias históricas.

Palabras Clave: ciencia ficción cubana, ucronía, Vladimir Hernández Pacín, Eric Flores Taylor, Jesús B. Minsal.

\begin{abstract}
This paper analyzes the characteristics of the post-soviet Cuban Science Fiction after the collapse of the Soviet Union and the Special Period in the Nineties. It focuses particularly on the newest production by Vladimir Hernández Pacín, Eric Flores Taylor and Jesús B. Minsal, among other authors. By analyzing their novels and short stories the author establishes a triple categorization of Cuban post-Soviet Science Fiction, depending on the major o minor presence of the Soviet and Russian referents. This three different approaches would be: first, the total absence of the Russia; second, identified as 'postsoviet nostalgia'; and the third one, categorized as 'uchronia', in which Russia plays still, and despite the historical circumstances, an agent and active role.
\end{abstract}

Key Words: Cuban science-fiction, uchronia.

DOI: 10.7203/KAM.5.4602 
Yoss. Lo que quedó de Cuba...

Probablemente si a los europeos y norteamericanos del período entreguerras del siglo XX, habituados a que los productos manufacturados japoneses que conocían fueran el epítome de lo barato y de baja calidad, les hubieran dicho que desde los años 60 de ese mismo siglo la excelencia de la electrónica nipona se volvería emblemática, con marcas como Sanyo, Sony, Mitsubishi, Toshiba y otras tantas, lo habrían considerado una simple broma pesada... amén de suceso de muy improbable advenimiento.

También es casi seguro que si a algunos de los entusiastas lectores de Amazing Stories y otras populares revistas pulp de ciencia ficción ${ }^{1}$ de los años 40 y 50 se les pudiera trasladar, máquina del tiempo o algún otro cronoartilugio mediante, al día de hoy, la mayoría quedarían profundamente decepcionados: no existen colonias en otros planetas de nuestro Sistema Solar, los viajes interestelares están aún lejos de ser una realidad cotidiana, y tampoco hay coches voladores, trajes que se laven solos, robots personales ni sintetizadores de alimentos. A aquellos soñadores, en especial, los diseños de nuestros autos y aviones les parecerían simplones, romos y feos, exentos de esa profusión de aletas superfluas pero supuestamente (y sólo supuestamente) aerodinámicas que distinguía a los productos de la General Motors en dichas décadas y que ellos se acostumbraron a asociar con el aspecto visual que tendría el gran desarrollo tecnológico del mañana.

Esta sensación de desilusionado desconcierto ante un futuro que resulta no haber sido lo que iba a $\operatorname{ser}^{2}$ aparece muy bien descrita en varios cuentos de CF hoy devenidos clásicos. Como El continuo de Gernsback ${ }^{3}$, de William Gibson: el protagonista, diseñador que llega a obsesionarse con dicha estética, que pudiera llamarse retrofuturista, llega a tener visiones de los habitantes del mundo que prefiguraba, y comprende cuán ajeno resulta este a su propia realidad: es un universo alternativo, una especie de ucronía; un futuro que nunca llegó a realizarse, que jamás fue.

La causa de ambas clases de incredulidad y decepción es la misma: la imaginación lineal. O, en palabras simples, la tendencia inconscientemente conservadora del ser humano (a menudo reforzada por trasnacionales que controlan un mercado determinado y apuestan por su estabilidad en años venideros) a presuponer que si hoy hay autos, mañana también los habrá, aunque sean más rápidos y sofisticados; que

\footnotetext{
1 En adelante, usaremos la abreviatura CF en vez del término extendido “ciencia ficción” al que convencionalmente representa.

${ }^{2} \mathrm{Y}$ admitimos que en el fondo esta puede ser sólo otra versión del pesimista slogan “el futuro ya no es lo que era”, con el que muchos en el fandom de la CF denuncian nada menos que a... la realidad, por quedarse por debajo de sus expectativas $¿ \measuredangle ! !$

3 The Gernsback continuum (1981) aparecido en el número 11 de la revista Universe y posteriormente incluido en la antología Mirrorshades (Gafas de Espejo, en una no muy exacta traducción al español).
} 
Yoss. Lo que quedó de Cuba...

si hoy hay correo, mañana lo habrá, aunque pueda ser neumático. Siempre más de lo mismo, pero mejor y más eficiente. Y nihil novum sub sole ${ }^{4}$, que todo va bien como va....

El futuro ha sido y por lo visto será siempre un enigma. Pocas son las mentes, científicas o no, capaces de prever con cierta exactitud, tanto en la vida como en la literatura, las grandes transformaciones que determinados cambios aparentemente pequeños pueden introducir. O, por el contrario, la forma en que grandes cambios que parecen drásticos podrán acabar amortiguándose contra el fondo conservador general.

Por sólo poner un par de ejemplos: cuando en el cómic Dick Tracy el intrépido detective protagonista usaba un reloj-comunicador de pulsera, nadie pensaba que llegaría el momento en que todos tendríamos un teléfono móvil en el bolsillo. Y cuando Isaac Asimov hablaba en diversas novelas y cuentos de gigantescas computadoras centrales, como Multivac y Macrotrón, carísimas y que consumían teravatios de energía para funcionar, muy pocos imaginaban que hoy habría PC portátiles de bajo costo, ni todo la revolución que han implicado Internet y los e-mails... aunque la Inteligencia Artificial que el Buen Doctor y tantos de sus colegas consideraban que estaba a la vuelta de la esquina aún parece estar bastante lejos de nuestras posibilidades. Y los más sofisticados robots actuales (como las últimas versiones del nipón Asimo, de Honda ¿pura coincidencia de nombre?) son también mucho más primitivos que sus positrónicos hombres mecánicos guiados por las famosas 3 leyes.

Por otro lado, quizás compensen los anteriores otros "incumplimientos" más afortunados, tanta catástrofe, natural o no, que nunca llegó a concretarse: tanto asteroide golpeando el planeta que nunca llegó, tanto imperio extraterrestre que nunca nos invadió ni esclavizó... y aquí ya huelgan los ejemplos

La CF no predice el futuro, ni para bien ni para mal, eso está claro. Pero, en tanto que literatura del cambio, históricamente sí ha prefigurado diversos mundos muy distintos ${ }^{5}$ al del momento en que fue escrita. $\mathrm{O}$ el actual: realidades en las que el contacto con otras especies pensantes extraterrestres ha ocurrido no con una guerra, sino de forma pacífica o incluso sin que nadie se diese cuenta, en el lejano pasado. Mundos en los que los robots se han rebelado contra nosotros (lo mismo... empezando por $R$. $U$. $R \cdot{ }^{6}$ y de nuevo Asimov, claro) o en los que la superpoblación y la contaminación ambiental han puesto a la

\footnotetext{
${ }^{4}$ Nada nuevo bajo el sol... podríamos haberlo dicho en español, claro, pero un latinazo certero siempre eleva el nivel teórico de cualquier cosa ¿no?

5 Y acertado de vez en cuando, claro; se podría decir que por puro azar estadístico: si se hacen suficientes predicciones, alguna acabará cumpliéndose... y será recordada.

${ }^{6}$ Robots Universales Rossum, obra de teatro escrita en 1920 por el checo Karel Cápek (1890-1938) y en la que por primera vez aparece el término robot, derivado del checo "robota" para trabajo duro.
} 
humanidad al borde de la extinción (Los mercaderes del espacio ${ }^{7}$; Todos sobre Zanzíbar ${ }^{8}$, buena parte de la obra de Ballard ${ }^{9}$ y tanta otra CF occidental más o menos catastrofista). Mañanas en los que poderes psi como la telepatía y la telequinesis se han vuelto reales y más o menos comunes (El hombre demolido; Las estrellas midestino ${ }^{10}$; Muero por dentro ${ }^{11}$,) y así un largo etc.

No obstante, un observador imparcial podría señalar como hecho cuando menos curioso el que el cambio global tal vez más relevante acontecido en las postrimerías del siglo XX, la caída del muro de Berlín, la desintegración de la URSS y el fin del socialismo real ente 1989 y 1991, tomara al género, metafóricamente hablando, “con los pantalones bajados".

Parece simple encontrar disculpas de peso para tal sorpresa.... pero al final todas acaban relacionadas con la incapacidad del ser humano para imaginarse ciertos cambios, y mientras más drásticos, peor. Algo que podríamos llamar inercia mental, si ya no hubiese sido bautizado como imaginación lineal, linealidad imaginativa... o más bien, falta de ella.

El caso es que, tras más de 70 años de existencia de la Unión Soviética, período en el que dejó de ser el único país socialista desde que a fines de la II Guerra Mundial engrosaron las filas de esta clase de estados varias naciones de Europa del Este, y posteriormente China, Viet-Nam, Cuba y Nicaragua, a muchos les parecía que dicho modelo social estaba destinado a imponerse, a la larga. Si había sobrevivido al ataque de los nazis, y a tanto problema doméstico con minorías étnicas, intentos de "socialismo con rostro humano" como el de la Primavera de Praga en 1968, hambrunas por ineficiencia agropecuaria, etc... ¿por qué no darlo por eterno, vencedor y sanseacabó?

Y por cierto que la mayoría de la CF que se escribía en los países del pacto de Varsovia no dudó ni un instante en acogerse a esta opción... o no le permitieron probar otra. Esta "CF socialista canónica", asumía por cierto e indiscutible el optimista pronóstico de que al capitalismo, entrado en crisis definitiva, le quedaban pocos años. El futuro pertenecía por entero al socialismo, según planteaba un muy repetido lema, y las horas del modo de producción capitalista estaban contadas. Al máximo, los más osados y heterodoxos autores de CF de países socialistas se atrevían a prefigurar una guerra nuclear aniquiladora

${ }^{7}$ The space merchants (1953) de Frederick Pohl (1919-2014) y C. M. Kornbluth (1923-1958).

${ }^{8}$ Stand on Zanzíbar (1968) de John Brunner (1934-1995).

${ }^{9}$ James Graham Ballard (1930-2009) emblemático autor de CF británico de la New Wave.

10 The demolished man (1953) galardonada ese mismo año con el primer Premio Hugo de novela entregado por la SFWAAScience Fiction Writers of America Association. Stars my destination (1956) también conocida como jTiger! jTiger!. Ambas de Alfred Bester (1913-1987)

${ }^{11}$ Dying inside (1972) de Robert Silverberg (1935). 
Yoss. Lo que quedó de Cuba...

final, perreta egoísta en la que un imperialismo moribundo preferiría destruir la Tierra antes que dejarla intacta a los desposeídos ansiosos de justicia social que les habían arrebatado el poder ${ }^{12} \ldots$ o más a menudo simplemente evadían el caracterizar ideológica o socialmente sus prefiguraciones ${ }^{13}$.

En cuanto a Occidente, muchos autores de CF de prestigio, sobre todo entre los más preocupados por el realismo, también parecían haber acabado por resignarse al hecho de que el campo socialista estaría ahí por un buen rato, y que durante muchos años la URSS seguiría siendo un poder militar a tomar en cuenta ${ }^{14}$.

Tal vez los marxistas tenían algo de razón, después de todo, y aunque el capitalismo no se enfrentara a su crisis definitiva, como ellos decían, tampoco parecía ya capaz de vencer a su rival socioeconómico y desterrarlo de la realidad global...

Si bien es cierto que la mayoría de los autores de CF capitalistas, sencillamente, tal vez por no saber cómo tratar con la "variable comunista" se limitaban a esquivar el bulto, o sea, a no incluir sociedades basadas en dicho modo de producción en sus "ecuaciones de futuro" 15 ... por lo general sin molestarse siquiera en aclarar cómo había desaparecido el molesto Segundo Mundo del panorama sociopolítico terrestre del futuro ${ }^{16}$.

12 Ese es precisamente el argumento de la monumental novela Espiral, del cubano Agustín de Rojas Anido (1949-2011) segundo Premio David otorgado a una obra de CF, en 1980, y que este año reedita la editorial Letras Cubanas.

${ }^{13}$ Como el polaco Stanislaw Lem (1921-2006), sin dudas el autor de Europa del Este mejor conocido en Occidente, aunque su firme negativa a describir en sus libros un mañana "ideológica y socialmente correcto" le acarreó no pocos problemas en su patria. Problemas que también enfrentaron con varios e sus libros los mejores autores soviéticos, los hermanos Arkadi (1925-1991) y Boris (1933-2013) Strugatski, pese a que ellos sí hablaban de un futuro comunista... bien que con algunos problemas que los ortodoxos líderes del PCUS debieron parecerles poco edificantes.

${ }^{14}$ Como el derechista y militarista Jerry Pournelle (1933). En las novelas de su serie "Historia del Futuro" la Unión Soviética y los EUA forman una improbable alianza entre ideologías opuestas: el Codominio, que se vuelve la fuerza militar encargada de controlar la expansión y colonización de otros mundos.

15 Una notable excepción fue la antropóloga y escritora Ursula K. LeGuin (1929), que tal y como había hecho con los estereotipos del sexo en La mano izquierda de la oscuridad (1969), y con la guerra de Viet-Nam en El nombre del mundo es bosque (1972) se aventuró a indagar sobre un socialismo de tipo anarquista coexistiendo con el capitalismo en su monumental novela Los desposeídos (1974) no en balde considerada a la altura de distopías clásicas del género como $U n$ mundo feliz (1932) de Aldous Huxley (1894-1963) y 1984 (1949) de George Orwell (1903-1950).

16 ¿Se necesitan ejemplos? pues sobran: William Gibson, Larry Niven, Bruce Sterling, Arthur C. Clarke... la lista sería interminable. 
Sin embargo, lo imprevisto ocurrió, y sin avisar: cuando menos se esperaba, la economía del socialismo, lastrada por los inmensos gastos de la carrera armamentista ${ }^{17}$, no pudo ya ofrecer el mínimo nivel de confort a sus ciudadanos, y se derrumbó. El Politburó pasó al basurero de la historia, las dos Alemanias se unieron, y aunque la historia no se acabó ahí mismo, como profetizara sombríamente Fukuyama, el mundo, tras casi 45 años de Guerra Fría, sí respiró aliviado ipor lo visto la tan temida hecatombe nuclear no se produciría, al menos de momento!... y tuvo que aprender a vivir en el nuevo orden unipolar $^{18}$.

\section{¿Y qué pasó entonces en Cuba?}

Un artículo literario no es el espacio idóneo para analizar lo justo o equivocado de la decisión de Fidel Castro de mantenerse inclaudicablemente socialista, incluso sin la hasta ese momento crucial ayuda económica del "hermano mayor" soviético y el resto del CAME. Tampoco es el objetivo de este trabajo hacer un recuento de las difíciles condiciones de vida y trabajo que la población de una Cuba abocada a la carestía debió afrontar ${ }^{19}$ durante la década del 90, en el muy eufemísticamente bautizado Período Especial en Tiempo de Paz. Ya mucho se ha escrito y seguirá escribiendo al respecto, por otro lado.

Nuestro propósito, mucho más modesto, es sólo analizar brevemente cómo se ha desplegado o manifestado en la ficción nacional lo que muchos analistas han dado en llamar espacio postsoviético: en este caso concreto, cómo la ausencia en el presente-futuro de la URSS, en tanto que poder factual y referente sociopolítico ${ }^{20}$, ha sido y está siendo abordada en la más reciente producción de CF cubana.

En primer lugar, cabe señalar como antecedente necesario para una mejor comprensión del panorama socioliterario del género en Cuba el que, en décadas anteriores, sobre todo en la de los 80, y debido por supuesto a la fuerte presencia económica, militar y social soviética en la isla, muchos autores

\footnotetext{
17 Irónicamente, la CF tuvo algo que ver en el derrumbe; según casi todos los analistas, lo que dio el puntillazo definitivo a la ya maltrecha economía soviética y precipitó la glasnot y perestroika de Mijaíl Gorbachov que condujeron a la caída de la URSS, fue que la alta cúpula del PCUS comprendió la imposibilidad indiscutible de mantenerse a la altura de los gastos que EUA calculaba para su Iniciativa de Defensa Estratégica... familiarmente llamada "Guerra de la Galaxias" por el presidente que más abogó a su favor, el ex actor Ronald Reagan (1911-2004).

18 Bueno, ya no tanto; la nueva Rusia capitalista reestructurada de Putin es un indiscutible poder militar global y un rival económico creciente para los EUA y la Unión Europea. Sin contar con las variables de China, Brasil e India en el delicado y complejo equilibrio ¿unipolar? ¿tripolar? ¿multipolar? de la política internacional del siglo XXI.

${ }^{19}$ Es decir, lo que no emigraron, que fueron muchos. Con una población actual de unos 11 millones de habitantes, se calcula que Cuba tiene otros 4 millones de ciudadanos viviendo en diferentes naciones extranjeras, sobre todo Estado Unidos.

${ }^{20} \mathrm{Y}$ en contadas ocasiones, su sustitución por una Rusia igual de poderosa y expansionista, económica y militarmente hablando, pero mucho menos ideologizada, claro.
} 
eligieron o tuvieron que adoptar cierto compromiso ideológico con el futuro socialista ${ }^{21}$. Cuyo grado variaba mucho, yendo desde la simple mención (lo más frecuente, por suerte) de la URSS o el socialismo como elementos más o menos fundamentales del mañana, hasta extremos francamente ridículos, como el de la lamentable novela Expedición Unión-Tierra ${ }^{22}$ en la que Moscú era la capital de la tierra comunista y el personaje protagónico un soviético llamado Fiódor, relegándose al único carácter cubano al secundario rol de cocinera... negra y gorda, para más tópico.

En cuanto a los años 90, la década del Cambio, de la Desilusión o del Período Especial, según prefiera llamarla cada uno, ya fuera por falta de inspiración de los autores de la década anterior, que no sabían o no se atrevían a escribir una CF acorde a los nuevos tiempos... o más bien simple imposibilidad editorial (la cantidad de publicaciones, no sólo de libros, sino también de revistas, descendió notablemente en ese lapso) lo cierto es que sólo se publicaron 3 libros de $\mathrm{CF}^{23}$, y todos ellos habían sido escritos durante la década anterior.

Lástima, porque habría sin dudas resultado muy interesante ver cómo el género abordaba tan crucial etapa de transición, que en otros géneros narrativos nacionales produjo fenómenos antes impensables, como el realismo sucio de Pedro Juan Gutiérrez o la nueva novela policíaca de Leonardo Padura y Lorenzo Luna Cardedo.

Entonces, y a falta de CF cubana publicada en los $90 \ldots$ al menos en el país ${ }^{24}$, analizaremos a varios autores y obras de CF cubana publicados (o a punto de serlo, en algún que otro caso...) dentro y fuera de la isla durante el último decenio (2004-2014). A los que, en orden creciente de compromiso ficcional con el espacio postsoviético, dividiremos a priori en 3 grupos.

\footnotetext{
${ }^{21}$ Los interesados en ahondar más en el tema de la influencia de la CF soviética en la cubana durante los años 80 pueden consultar nuestro trabajo Los futuros de la hoz y la palma, incluido en la recopilación de artículos sobre la CF La quinta dimensión de la literatura (2012).

22 (1981), Richard Clenton Leonard.

${ }^{23}$ Fueron, respectivamente: los libros de cuentos Por el atajo (1991) de Bruno Henríquez (1947); y La poza del ángel (1994) de Gina Picart Baluja (1956); más la novela Sider (1994) de Angel Arango (1926-2012).

${ }^{24}$ Ya que sí se escribió mucho, y en el exterior aparecieron unas pocas novelas claves, como (aunque parezca inmodesto señalarlo) el fix-up distópico Se alquila un planeta (2001) del autor de este trabajo (nacido en 1969) que posteriormente ha visto traducciones al francés (Planete a louer, 2011) y el inglés (A Planet for rent, 2014). Y escritas en esa época, aunque publicadas ambas algo después, (respectivamente en 2001 y 2003) son también las novelas Garbage Land y Orlan veinticinco, del cubano residente en Barcelona Juan Abreu.
} 
-Primero, los que sin haber hecho antes demasiado hincapié en la existencia de la URSS como poder político militar alternativo a Occidente, al desaparecer eta nación dejaron simplemente de mencionarla, sin culpabilidad de ninguna clase por ese "borrón y cuenta nueva”.

-Segundo, los que, probablemente por ese curioso mecanismo de la psiquis humana de desear lo prohibido y escaso y renegar de lo impuesto y omnipresente, evidencian mayores o menores trazas de lo que podríamos llamar "nostalgia postsoviética", actitud que se manifiesta en el elogio más o menos teñido de añoranza a las manufacturas de esta nación (o de Rusia, su heredera natural) o a cualquier otra clase de cualidades y/o características culturales de la idiosincrasia eslava.

-Y, tercero, a quienes, en un curioso mecanismo de reelaboración ucrónica del presente y el futuro, han otorgado a los actuantes rusos ¡o incluso anacrónicamente soviéticos! papeles cruciales en sus cosmogonías privadas.

Comencemos entonces por el primer caso, que ejemplificaremos con la obra narrativa de Vladimir Hernández Pacín (1966, y residente en Barcelona, España desde 2000) sobre todo en la recogida en el volumen de cuentos Hipernova (y otras singularidades tecnológicas) publicado en 2013 en Cuba ${ }^{25}$.

En los 10 relatos que conforman esta selección de 472 páginas, divididos en 3 secciones ${ }^{26}$, prácticamente apenas se menciona a la Unión Soviética, ni con nostalgia ni con resentimiento: simplemente, es un pasado ya remoto y casi vergonzoso, una vía muerta de la que nadie quiere hablar: un ayer omitido. La nueva Cuba, cuando sirve de escenario para la acción, como en el relato Hipernova, es un país más del Tercer Mundo, capitalista, claro, y cuya principal entrada económica es el peaje que pagan los usuarios de la Autopista Transcaribeña que atraviesa de norte a sur la isla y su megalópolis

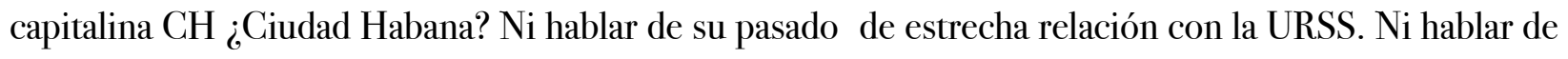
su ayer socialista, ni de cómo el antiguo sistema colapsó en el futuro. Cuando más aparecen referencias ocasionales a la Rusia capitalista, por la mafia y la tecnología militar, barata y sencilla de conseguir, aunque eficacísima, sobre todo, características definidas desde los convulsos 90 de Yeltsin.

En su mayoría, se trata de relatos ciberpunk muy al estilo de Gibson y Sterling, que abordan temas clásicos como el del surgimiento de las IAs, en la primera parte, la lucha con otra especie inteligente,

\footnotetext{
${ }^{25}$ Aunque prácticamente las mismas narraciones ya habían aparecido en 2009 en España bajo el título de Sueños de Interfaz.

${ }^{26}$ Las secciones son las siguientes, con los relatos que las integran, por orden: FUTURO CERCANO: Sueños de interfaz, Semiótica para los lobos e Hipernova; FUTURO LEJANO: El oráculo de Penrose, Emperatriz, Signos de guerra y Langosta pálida; y FUTUROS ALTERNATIVOS: Kretacic Rap, Némesis y Luciérnagas.
} 
insectoides coloniales a medio camino entre ramen y varelse ${ }^{27}$, es decir, con los que es posible comunicarse... pero con grandes dificultades, y la trascendencia humana, el futuro del sexo y otros, en la tercera. Es un libro que habría podido firmar cualquier autor, en el que los 30 años de presencia de la URSS en la isla y su ¿obsoleta? ideología marxista apenas tienen ningún papel. Hasta el punto de que se podría especular incluso que el autor se toma más o menos abiertamente una especie de revancha personal a cuenta de la sobreexposición que sufrió (como tantos cubanos nacidos y crecidos durante las 3 décadas de casi omnipresencia soviética en la vida cubana) a los pomposos ideologemas oficiales de "la inquebrantable amistad URSS-Cuba" "los destinos indisolublemente ligados" y compañía... simplemente borrando de un plumazo toda posible influencia de la antigua Unión Soviética en el mundo futuro.

Claro que Hipernova no es el único libro de CF cubana publicado en el siglo XXI que obvia casi cualquier referencia a los ruso-soviéticos. Otro autor ya publicado de la época del "auge soviético" como Roberto Estrada Bourgeois (1950) que en su primera novela del género, Trenco (1986) describía un futuro vagamente socialista ${ }^{28}$, sin embargo en libros posteriores como Bosque (2006) y La puerta del mar cuántico (2008) apenas si menciona tampoco al Este de Europa.

¿Podría entonces aventurarse la teoría alternativa de que los viejos hábitos de autocensurarse cualquier crítica al modelo comunista del futuro mantuvieron, en cierto modo, vigencia, incluso tras la caída del campo socialista?

Es una explicación atractiva, pero a la vez difícilmente realista; otros autores mucho más jóvenes ${ }^{29}$, para los que por obvios motivos cronológicos la Unión Soviética y el Pacto de Varsovia ya constituyen apenas referencias históricas casi igual de remotas que la Triple Entente de la Primera Guerra Mundial o el Axis en la Segunda, como Gabriel J. Gil Pérez (1987) o Elaine Vilar Madruga (1989) en libros como la recopilación de cuentos Por casa tengo el espacio (2012) del primero, o las novelas Promesas de la Tierra Rota (2012) y Salomé (2013), tampoco hacen referencia alguna a rusos o soviéticos. Y está claro que no puede hablarse aquí de "venganza por ninguneo", ni tampoco de "autocensura preventiva”.

\footnotetext{
27 Según la célebre clasificación creada por el escritor Orson Scott Card (1951) en su Saga de Ender. Ramen son las entidades extraterrestres con las que es posible comunicarse; varelse, aquellas con las que no se puede establecer un diálogo, a las que incluso cuesta trabajo reconocer como racionales.

28 Aunque en la edición revisada del 2011 la mayoría de estas referencias fueron suprimidas.

29 Ambos de la tercera generación de escritores cubanos de CF, nucleada en torno al taller literario fantástico Espacio Abierto, y que desde la segunda década del siglo XXI están publicando su obra cada vez con mayor frecuencia dentro y fuera del país.
} 
Pero veamos ahora el segundo caso, para ejemplificar el cual hemos elegido a la novela Entre clones y tambuches, del dueto Eric Flores Taylor (1982) y Jesús B. Minsal (1974), un texto que, si bien aún inédito, deberá aparecer en 2016 en la Colección Ámbar de la editorial Gente Nueva ${ }^{30}$... por lo que tendrán que perdonarnos una breve reseña que trataremos de que no caiga en el spoiler descarnado.

Nacido uno y crecidos ambos en el actualmente llamado por algunos "decenio de la prosperidad engañosa”, o sea, los años 80, Flores y Minsal, combinan armónicamente sus disímiles talentos narrativos para relatar las aventuras de una rara mezcla de delincuente y pequeño empresario: Antonio Reuterio Yerena López, más conocido en su barrio semimarginal capitalino como "Tony el tambuchero" o "Tony el mago".

$\mathrm{Qba}^{31}$, la singular Cuba del futuro en la que estas peripecias transcurren constituye, a grandes rasgos, una distopía respecto a la actual: un capitalismo salvaje se ha enseñoreado de la isla, y corporaciones chinas y europeas luchan por los espacios comerciales del rico mercado emergente. Tony, con un complejo pasado que incluye por lo visto haber sido combatiente en no importa cuál guerra, tiene ahora un negocio legal que apenas si alcanza para pagar sus impuestos al gobierno; vende comidas: los tambuches... y otra actividad ilegal (como tantos cubanos de hoy) pero mucho más próspera, alrededor de la cual se desarrollará la intriga de la historia: fabrica clones humanos con fecha de caducidad fija, para desahogos psicológicos u otras actividades más o menos inconfesables.

No relataremos aquí en detalle las múltiples vicisitudes del tambuchero enfrentado a diversos grupos trasnacionales y políticos autóctonos de presión, así como a las fuerzas policiales de élite habaneras, ni profundizaremos en sus prácticas de santería, la religión sincrética afrocubana, que por momentos rozan la alta tecnología, sino que vamos a centrarnos únicamente en algo que el narrador nos informa ya en el primer capítulo, al presentarnos breve pero claramente a su antihéroe:

Tony tiene un implante ruso clase Ómicron en la pierna izquierda, una maestría en bioquímiK, fue miembro interino de la RepO KyoLager, es dueño de una cantina en su propia casa donde hace comida para la calle, cría animales de corral en un patio interior y como todo habitante que se respete del TeknoArchipiélago, posee un negocio ilegal y clandestino $(. . .)^{32}$

\footnotetext{
${ }^{30}$ Que durante el último lustro ha publicado casi el $80 \%$ de la literatura fantástica editada en Cuba, gracias sobre a los nunca demasiado bien ponderados buenos oficios de su editora Gretel Ávila, así también como de la actitud positiva hacia el género del hasta 2014 director de la editorial, Enrique Pérez Díaz.

${ }^{31}$ Sí, no es error: los autores se toman grandes libertades (sobre todo de tipo fonético-literal) con la ortografía del español en su novela, como quedará luego en evidencia en los fragmentos que insertamos en el cuerpo de este artículo.

32 Entre clones y tambuches, página 1 del manuscrito original.
} 
El implante Ómicron ruso en cuestión, podría definirse como un sofisticado exoesqueleto parcial para pie y pantorrilla (que no una prótesis) con control de sobrecargas inerciales. Muy útil para saltar bien lejos o tomar tierra cayendo desde grandes alturas, lo mismo que para golpear de forma en extremo contundente a cualquier enemigo, como se evidencia luego claro en un largo y crucial capítulo de persecución.

Y es precisamente este artefacto, que le fuera insertado al protagonista para suplir la mutilación sufrida durante una especie de accidente sufrido en su juventud durante la práctica de un deporte urbano de alto riesgo deportivo sobre el que no daremos mayores detalles, el que adquiere connotaciones simbólicas casi arquetípicas en la novela.

El Ómicron es descrito un par de veces como grande, pesado, tosco y feo... pero sin fallos, a prueba de todo, prácticamente indestructible, y sobre todo, ofrece prestaciones de impulso y amortiguación muy por encima de las que podría brindar cualquier equivalente occidental existente en el mercado, aún siendo más moderno.

$($.... ¡La Ómicron Rusa! ¡Esa sí fue una serie con calidad! No existe en el mundo entero un implante mejor (sin importar que sea «bolo»). Combina la dureza de los Lambda y los avances de la clase Xi. Los que vinieron después (Made in cualquier otro lugar) no son más que actualizaciones cada vez más perecederas, hechas de flexyplast y hasta acrilex, en lugar de usar mercurio semi-sólido como en las series anteriores $(. . .)^{33}$

Los autores establecen aquí una (al menos en Cuba) tradicional comparación ente las cualidades tradicionales de las manufacturas o productos industriales soviético-rusos ${ }^{34}$ y los occidentales.

(...) Según la propaganda, las series posteriores mantienen los mismos resultados que el Ómicron Ruso en las pruebas de campo. Además no es necesario renovar el material y su capacidad de procesamiento de información del entorno es mucho mayor. Sin embargo, yo nunca he visto un $\mathrm{Pi}$, Ro o Sigma (hechos de acrilex) abollar la carrocería de un almendrón como lo hizo el Ómicron de Tony. Ni siquiera los Tau, Ýpsilon, Fi y Ji (de flexyplast, a prueba de balístiK) son capaces de semejante proeza. No por gusto la teknología rusa (aunque en ocasiones obsoleta y siempre carente de estética) es tan valorada en el mundo entero por su durabilidad y resistencia ¿y quién

\footnotetext{
33 Página 37 del manuscrito original.

34 Familiarmente llamadas "bolos", ¡y no sólo en Cuba! Se supone que el término es derivado de "bolchs", abreviatura coloquial de bolcheviques, pero hay fuertes discusiones al respecto: otro origen muy plausible podría ser como alusión directa al diseño tosco "boludo" con aristas sin pulir y a menudo rebabas o sobrantes, que los caracteriza.
} 
Yoss. Lo que quedó de Cuba...

mejor que un Qba-no para apreciar a los queridos «bolos», más aún después de compararlos con los chi-nos?(...) 35

Pueden ser modelos vigentes hace décadas sin modernizaciones, feos, simples, pesados y concebidos sin pensar en la comodidad, pero a cambio resultan fiables y casi eternos ${ }^{36}$. Mientras que la alternativa, los diseños actualizados y/o mejorados frecuentemente, pueden, sí, ser hermosos, de refinada terminación y sofisticados en sus controles... pero también tienen fecha fija de caducidad: sencillamente están diseñados no sólo para quedar pronto obsoletos, sino que incluso se rompen o dejan de funcionar en pocos años, obedeciendo a una clara estrategia de mercado para obligar a sus poseedores a invertir en nuevos modelos.

Es un choque de paradigmas tecnológicos práctica e históricamente opuestos: el de lo duradero, simple y eficaz, aunque poco atractivo, contra el de lo en constante modernización pero virtualmente desechable ${ }^{37}$. Socialismo contra sociedad de consumo. Y, cuando los parámetros que interesan son la efectividad y confiabilidad, no cabe duda de cuál de ellos resulta preferible.

Hasta el punto de que, cuando tras haber golpeado a diestra y siniestra a varios miembros de las fuerzas del orden que trataban de capturarlo, el tambuchero es finalmente atrapado por la autoridad, se le retiene de forma cautelar (y muy prudentemente) el implante de marras del que tan contundente uso había hecho antes, para evitar cualquier ruptura del acuerdo por su parte:

(...) Por último: como garantía del cumplimiento del presente contrato, la parte capitalista retendrá el implante Ómicron de la parte asalariada...

- ¡NO! -los gritos desesperados de Tony interrumpieron la exposición del trajea2 - ¡No, no! ¡Eso no, coño! ¡Te juro que voy a cumplir! Acere, la mercancía va estar en tiempo, pero por tu madre, no me quites el Ómicron.

\footnotetext{
35 Página 38 del manuscrito original.

36 Técnicamente podrían definirse como “concebidos con abundante reserva ingenieril”: o sea, para que puedan soportar largos desgastes, maltratos y escaso mantenimiento sistematizado, pero sigan funcionando a pesar de todo.

${ }^{37}$ Esta dicotomía la expresaban perfectamente los fusiles típicos de Occidente y Oriente: el M-16 y el AKM. El primero era ligero, sofisticado, construido con materiales de última generación en su momento, como el plástico, cómodo, incluso hermoso... pero también delicado y frágil ante las inclemencias meteorológicas y del terreno, complejo y de fácil rotura, sus magazines de alimentación cargaban apenas 20 disparos, y no admitía el acople de un aditamento tan "salvaje y primitivo “ como la bayoneta. Mientras que el AKM, fusil tosco y simplísimo, era pesado, con madera en vez de plástico e incómodo con su lago cargador de 30 disparos... pero podía hacer fuego incluso lleno de arena y luego vaciado, bajo el agua, y estaba equipado para el acople de una versátil bayoneta. Expertos tiradores opinan que el M-16 era una buena arma... en condiciones urbanas controladas, pero la rusticidad y fiabilidad del AKM son aún hoy proverbiales.
} 
Las lágrimas del mago tomaron por sorpresa a los presentes (en especial al corpora2).

-Lo siento, Antonio -dijo acercándose al prisionero para susurrarle al oído -No nos dejaste otra opción. Agradece que lo tuyo es un implante potenciador y no una prótesis, por lo menos vas a poder llegar hasta el hospital más cercano. ¿Qué quieres que haga? Has jodido demasiado con la teknología rusa y los FIANA no se van a ir sin llevársela. Cuando termines el trabajo te lo devolveremos, ¿me entiendes? (.... $)^{38}$

Este alto grado de apego emocional a un artefacto de manufactura "bola" resulta singularmente paradójico para el que conoce o recuerda la clásica actitud popular cubana hacia dichos objetos, su estética y prestaciones, en las décadas del 60, 70, 80 y 90: irónica, despectiva o escéptica en el mejor de los casos. Aunque, como enésimo ejemplo de la doble moral pública y privada que caracteriza a las sociedades socialistas, no se admitiera el denostarlos abierta y públicamente, llegándose en ocasiones al extremismo de interpretar cualquier crítica ${ }^{39}$ (o, por contraste, alabanza a los productos capitalistas) como "diversionismo ideológico" o "ingratitud hacia los hermanos soviéticos que tan desinteresadamente ${ }^{40}$ nos ayudaban a dejar atrás el subdesarrollo".

Tal tácita inversión de significantes de Flores y Minsal en su novela constituye, pues, un guiño particular a la memoria del pueblo cubano, a la vez que una incursión en toda regla en el espacio ficcional postsoviético.

Podríamos, por supuesto, citar otros ejemplos de esta clase de giro de paradigmas en algunos cuentos o novelas de la más reciente CF cubana, pero preferimos abstenernos, en aras de la brevedad y

\footnotetext{
${ }^{38}$ Página 68 del manuscrito original.

${ }^{39}$ Veto que se extendía incluso a productos culturales, y por tanto, altamente subjetivos: muchos recordarán la dura sanción laboral que sufrió a mediados de los años 70 el célebre actor cómico Enrique Arredondo (1906-1988) cuando su popular personaje de Bernabé, en una de las trasmisiones (entonces en directo) del popular programa de humor costumbrista Detrás de la fachada, amenazó a su nieto con que si no se portaba bien lo castigaba a ver "muñequitos rusos" (dibujos animados tanto de la URSS como de otros países de Europa del Este, en el argot popular cubano). Este veto más o menos velado, que nunca explícito, se mantuvo hasta que, a principios de los años 90, el propio Fidel Castro se permitió por primera vez, en un muy recordado discurso público y de difusión nacional, criticar a los camiones soviéticos como "despilfarradores irracionales de combustible": una triste verdad de Perogrullo que todos los chóferes y mecánicos de Cuba conocían desde décadas antes.

40 Lo "desinteresado" de la ayuda soviética siempre fue asunto muy polémico: lo cierto es que, desde el "portaaviones insumergible" que fue Cuba para Kruschov cuando la Crisis de los Misiles o de octubre (1962) hasta la "avanzadilla de fomento de revoluciones en el III Mundo", la isla siempre pagó de forma geopolítica o directamente militar (como en Angola y Etiopía) dicha colaboración, y para sus habitantes, no existía ninguna deuda real. Aunque de todos modos el tema siguió siendo más o menos tabú hasta el pasado 2014, cuando el presidente Vladimir Putin (1952) durante su breve visita a la nación caribeña, anunció la condonación de la deuda económica externa de Cuba que había heredado Rusia de la disuelta URSS, ascendente a varios miles de millones de dólares... bien que no de sus intereses: que toda generosidad tiene un límite.
} 
Yoss. Lo que quedó de Cuba...

por considerar que ninguno aportaría elementos nuevos ni enriquecedores a lo que hemos establecido arriba.

Pasemos entonces al tercer caso. O sea, el desempeño casi protagónico de actuantes rusos o soviéticos en una cosmogonía cubana. Concretamente, en el universo ucrónico de Habana Underguater, creado por Erick Jorge Mota Pérez (1975), y del que hasta ahora hay publicados un libro de cuentos y una novela ${ }^{41}$.

La peculiaridad que más nos interesa para este trabajo del meticuloso worldbuilding creado por Mota es que la Guerra Fría tuvo resultados exactamente inversos que en el "mundo real”: los Estados Unidos, que la perdieron, quedaron desintegrados, mientras que la URSS, victoriosa, se mudó con toda su población a la órbita, conformando los Estados Soviéticos del Espacio, que desde arriba supervisan la estabilidad de su "Pax Soviética".

Son, de hecho, el poder militar y económico rector del planeta entero... incluida una Cuba muy diferente de la actual: con la central electronuclear de Juraguá (Cienfuegos) terminada y operando, pero balcanizada en diversas ciudades-estado. Excepto en el caso particular de La Habana, ahora coloquialmente underguater: medio inundada tras un gran huracán (el Ciclón) por efecto de un monumental dique contra penetraciones del mar de factura rusa que funcionó mal, y dividida en barrios controlados por distintas facciones armadas de carácter ideológico, religioso o ambas. Como la FULHA (Fuerza Unida de La Habana Autónoma), la CUC ${ }^{42}$ (Corporación Unión Católica), los babalawos, los paleros y la Fundación Charles Manson, que alquila asesinos psicópatas a sueldo.

(...) El mar se agitaba en un oleaje moderado que rompía en la línea de edificios derrumbados de la franja del Malecón. El Mago contempló el extremo de la entrada de la bahía, la playa del Túnel, la torre semihundida del Castillo de la Fuerza y la Giraldilla oxidada que oscilaba por la acción del viento.

Sobre la pulida superficie de la plataforma de lanzamiento, las diminutas figuras de los técnicos de cohetería ponían a punto el próximo vuelo a la órbita. La torre de control, ubicada sobre uno de los campanarios de la Vieja Catedral, contrastaba con las estructuras modernas de metal y plástico que formaban las terminales y los hangares del cosmopuerto.

\footnotetext{
${ }^{41}$ Ambas en 2011 por la editorial norteamericana de impresión por demanda Atompress, si bien la novela debería aparecer en Cuba en 2016 por Caja China, la pequeña editorial del Centro de Formación Literaria Onelio Jorge Cardoso de la capital, dirigido por Eduardo Heras León (1940).

${ }^{42}$ Se trata de acrónimos que, irónicamente, hacen referencia a denominaciones oficiales o coloquiales de la moneda libremente convertible cubana: cuc, fula.
} 
Al otro lado de la bahía, la hilera de instalaciones del comando central de FULHA en La Cabaña encendían las luces. Los helipuertos a lo largo de Casa Blanca encendían reflectores que apuntaban al cielo mientras la guardia operativa despegaba para su ronda nocturna sobre la ciudad. Lanchas torpederas se movían por la bahía de aguas negras escudriñando los pecios oxidados de los barcos rusos, los almacenes semihundidos de Puerto Habana y el laberinto de fachadas, postes de luz y columnas de lo que fue en un tiempo el centro histórico (...) (Mota, 2011: 102).

También hay balseros a la inversa, que tratan de entrar a Cuba desde la empobrecida América del Norte, e IAs autoconscientes en la Red, que se han asimilado a las deidades sincréticas afrocubanas, los orishas... lo que resulta un reto particular para los hackers criollos.

Obviamente, además de ucronía ${ }^{43}$, se trata de una distopía ${ }^{44}$ por derecho propio: una sangrienta historia del futuro, donde diversas y cruentas guerras coloniales emprendidas por los rusos para mantener su hegemonía son elemento rector:

(...)Ese tipo no es ningún comemierda, lo parieron las tropas especiales rusas.

- ¿Antes del Ciclón?

- ¿Claro, 'mijo! ¿De qué otra forma? - Miguel se recostó a la silla y estiró los pies-. Un soldado profesional graduado con honores en Siberia. Formó parte de un comando spetznaz en Burundi hasta que los rusos completaron el programa de Migración Espacial Masiva. Rusia retiró sus tropas de África mientras se llevaban el país a la órbita, él fue reinsertado en la brigada pacificadora de Oklahoma. Cuando la guerra civil en California, desertó antes que los marines mexicanos entraran en Los Ángeles. Llegó hasta Miami, donde se ocultó hasta que Little Old Washington fue barrido por la bomba atómica orbital que tiraron los rusos en el 19.

-¿Qué hizo entonces?

-Lo que hacen todos. Se montó en una balsa y volvió a la patria.

-Un logro de la vieja escuela soviética (...) (Mota, 2011: 12)

Claro que no todos están de acuerdo con esta situación, aunque bien poco puedan hacer, comparativamente: la fuerza militar de los Estados Soviéticos del Espacio es demasiada. Pero al menos muestran su descontento:

\footnotetext{
${ }^{43}$ O sea, lo que pudo haber sido y no fue: de "u-cronos” ningún tiempo, por analogía con utopía: “u-topos”; ningún lugar.

${ }^{44} \mathrm{O}$ antiutopía, si se prefiere.
} 
(...)-¡Mierda, eso fue un Pulso Electromagnético! - dijo Pedro-.Los rusos tienen prohibida esa cosa.

- ¿Y a quién le importan los rusos ahora? -El camión chocó contra los blindados y quedó pegado a ellos. Arriba la torreta comenzaba a girar-. Esos traidores están dándose la buena vida en la órbita después que nosotros tuvimos que jamarnos el Ciclón. Si no les gustan los pulsos, que nos tiren una bomba atómica orbital y ya (...) (Mota, 2011: 83).

Obviamente, la novela está llena de cuidadosas referencias rusoides o sovietoides, como se refiera. Armas, frases en ruso, mención a instituciones cuerpos armados de esta nacionalidad:

(...) El uniforme era blanco, de corte militar, pero carecía de las insignias comunes en el ejército soviético.

- ¡Shtoi-tie, tavarish! (Alto ahí, camarada) -dijo uno de ellos mientras les hacía señas a Pedro y a Pablo para que se acercaran-.Dókument.

Pablo entregó los pasaportes a dos rusos altos. Estos se lo pasaron a su jefe que los ojeó con desconfianza en la mirada. El capitán de la Oprishnina alzó la vista hacia ellos y habló en un español confuso.

- ¿Vienen ustedes de Cuba?

-De La Habana, sí-Pedro acarició su pistola bajo la chaqueta.

- ¿Y qué buscan en Zukovgrado?

-Vamos al Cybernietivska bank (...) (Mota, 2011: 115).

Todos elementos de una convincente ambientación para este bizarro futuro de imperialismo soviético ¿o postsoviético? Que, curiosamente, ahora resulta de una estremecedora actualidad, después de los sucesos de Georgia en el 2008 y de Ucrania en el reciente 2014, en los que el viejo expansionismo ruso, que ha cambiado de cara pero no de alma desde el tiempo de los zares, ha vuelto a mostrar sus garras y sus claras intenciones de mantener un férreo control sobre los países circundantes de lo que considera su espacio geopolítico natural.

Y, por supuesto, tras tenerlos en casa durante casi tres décadas, los cubanos ${ }^{45}$ saben bien cómo se las gastan los tovarich... aunque, paradójicamente, tras la condonación de la vieja deuda con los soviéticos, las relaciones entre la mayor de las Antillas y el Kremlin parecen camino de estrecharse cada vez más.

${ }^{45} \mathrm{Al}$ igual que las poblaciones de los países ex satélites de la URSS en Europa del Este, claro. 
¿Tal vez un caso de "poner el parche antes de que salga el grano" para compensar la creciente influencia de los EUA en esta nueva era de restablecimiento de relaciones bilaterales? El tiempo lo dirá. De momento, cada año llegan a las playas de la isla más y más turistas rusos ¿nostalgia de su antigua presencia... o simple cálculo económico de costos?

A modo de conclusión, podemos decir que, tal y como ha ocurrido en otras manifestaciones $\operatorname{artísticas~cubanas~}^{46}$, al terminar los 90, la década más dura del Período Especial, con el inicio de la superación de la irracional actitud de esos años que pudiera definirse, grosso modo como de "ellos nos traicionaron...", la influencia de los 30 años de fortísima presencia ruso-soviética está volviendo a aparecer en la CF cubana. Las resentidas ignorancia o negación inicial de dicho período va siendo sustituida, y cada día más, por la inclusión orgánica de estas 3 décadas en el acervo imaginario de la nueva promoción de escritores fantásticos de la isla.

2 defebrero de 2015.

\footnotetext{
${ }^{46}$ Por sólo mencionar algunos ejemplos cinematográficos, podemos citar el filme Lisanka (2009), de Daniel Díaz Torres, comedia sobre la presencia rusa en Cuba durante la Crisis de Octubre, y los documentales Todo tiempo pasado fue mejor (2008) de Orizoe García Miranda; y Los bolos (2010), de Enrique Colina, ambos investigando desde distintos puntos de vista la presencia rusa en Cuba y sus huellas en la cultura popular. Por cierto que la revista Temas también agrupó en su número 36, aparecido en 2004, distintos artículos afines... entre ellos uno del autor de estas líneas, Lo que dejaron los rusos, gracias al cual ha acabado por considerársele (más bien exageradamente) una especie de autoridad nacional en este acápite.
} 


\section{Bibliografía citada}

Abreu, Juan (2001). Garbageland. Barcelona: Mondadori.

Abreu, Juan (2003). Orlan Veinticinco. Barcelona: Mondadori.

Arango, Ángel (1994). Sider. La Habana: Unión de Escritores y Artistas de Cuba (UNEAC).

Bester, Alfred (1953). The Demolished Man. Mount Shasta, California: Shasta Publishers.

Bester, Alfred (1956).The Stars My Destination/ Tiger, Tiger! London: Sidgwick \& Jackson.

Brunner, John (1968). Stand on Zanzibar. New York: Doubleday.

Cápek, Karel (2004). RUR. Robots Universales Rossum : obra en tres actos y un epílogo. Barcelona: Círculo de Lectores, S.A.

Clenton Leonard, Richard (1981). Expedición Unión Tierra. La Habana: Letras Cubanas.

De Rojas Anido, Agustín (1982). Espiral. La Habana: Editorial Unión.

Estrada Bourgeois, Roberto (1986).Trenco. La Habana: Letras Cubanas.

Estrada Bourgeois (2006). Bosque. La Habana: Editorial Gente Nueva.

Estrada Bourgeois (2008). Gente nueva. La Habana: Editorial Gente Nueva.

Gil Pérez, Gabriel J. (2012). Por casa tengo el espacio. La Habana: Editorial Gente Nueva.

Henríquez, Bruno (1991). Por el atajo. Santiago de Cuba: Editorial Oriente.

Hernández Pacín, Vladímir (2004). Sueños de interfaz. Barcelona: Ediciones B.

Hernández Pacín, Vladímir (2012). Hipernova (y otras singularidades tecnológicas). La Habana: Editorial Letras Cubanas.

LeGuin, Ursula K. (1969). La mano izquierda de la oscuridad. Buenos Aires: Minotauro.

LeGuin, Ursula K (1979). Elnombre del mundo es Bosque. Buenos Aires: Minotauro.

LeGuin, Ursula K (1974). Los desposeídos: una utopía ambigua. Buenos Aires: Minotauro. 
Minsal, Jesus B. y Flores Taylor, Eric (2016). Entre clones y tambuches (Inédito). La Habana: Editorial Gente Nueva.

Mota Pérez, Erick Jorge (2011). Habana Underguater. Atompress

Picart Baluja, Gina (1990). La poza del ángel. La Habana: Ediciones Unión.

Pohl, Frederik y Kornbluth Cyril M. (1953). The Space Merchants. New York: Ballantine Books.

Pournelle, Jerry (1989). Historia del futuro. Barcelona: Ultramar.

Silverberg, Robert (1972). Dying Inside. New York: Charles Scribner’s Sons.

Sterling, Bruce (ed.) (1998). Mirrorshades. Una antología ciberpunk. Barcelona: Siruela.

Vilar Madruga, Elaine (2012). Promesas de la Tierra Rota. La Habana: Editorial Gente Nueva.

Vilar Madruga, Elaine (2013). Salomé. La Habana: Casa Editorial Abril.

Yoss (2001). Se alquila un planeta. Madrid: Equipo Sirius.

Yoss (2012). La Quinta Dimensión de la Literatura. Reflexiones sobre la ciencia ficción en Cuba y el mundo. La Habana: Editorial Letras Cubanas. 